\title{
Cooperativas de trabalho: sustentabilidade, identidade jurídica e direito de contratar com a administração pública
}

\author{
Work cooperatives: sustainability, legal identity and right to contract with the public \\ administration
}

\begin{abstract}
Resumo
As cooperativas de trabalho apresentam-se como instrumento de promoção do desenvolvimento nacional sustentável, devendo-lhes ser assegurado o direito de atuar na esfera econômica em igualdade de condições com os demais tipos societários, inclusive no que tange ao direito de contratar com a Administração Pública. Nesse contexto, o presente estudo tem por objetivo realizar uma análise crítica a respeito dos institutos jurídicos que tratam sobre as condições para a participação de cooperativas de trabalho em certames licitatórios, além de analisar o entendimento do Tribunal de Contas da União (TCU) a respeito da proibição da participação de cooperativas de trabalho em licitações públicas. Para tanto, utilizou-se a pesquisa descritiva e exploratória de instrumentos normativos e jurisprudências do TCU que tratam sobre a participação de cooperativas em licitações públicas. Ao final, constatou-se que restam superadas as condições fáticas que deram ensejo a homologação do Termo de Conciliação Judicial firmado em 2003 entre o Ministério Público do Trabalho (MPT) e a União e a Súmula TCU 281, o que demanda o afastamento dessas normas do ordenamento jurídico vigente, ante a necessidade de atribuir máxima eficácia a nova normatização jurídica que trata sobre a matéria, sobretudo, as normas contidas na Lei das Cooperativas de Trabalho (Lei oํ 12.690/2012) e na Lei Geral de Licitações (Lei no 8.666/93).
\end{abstract}

Palavras-chave: cooperativismo, licitações públicas, desenvolvimento sustentável, competitividade.

\begin{abstract}
Work cooperatives promote sustainable national development, and have the right to act in the economic sphere on equal terms with other types of companies, including the right to contract with the Public Administration. In this context, the present study aims to carry out a critical analysis regarding the legal institutes that deal with the conditions for the participation of labor cooperatives in bidding contests, in addition to analyzing the understanding of the Federal Court of Accounts (TCU) regarding the prohibition the participation of labor cooperatives in public tenders. At the end, it was found that the factual conditions that gave rise to the approval of the Judicial Conciliation Term signed in 2003 between the Public Ministry of Labor (MPT) and the Union and the TCU 281 Precedent remain, which demands the departure from these rules of the current legal system, in view of the need to give maximum efficiency to the new legal norms that deal with the matter, above all, the rules contained in the Law of Labor Cooperatives (Law No. 12,690 / 2012) and in the General Bidding Law (Law No. 8,666 / 93).
\end{abstract}

Keywords: cooperativism, public tenders, sustainable development, competitiveness.

Erica Almeida Leal', Catrine Cadja Indio do Brasil da Mata"I , Ferlanda Luna ${ }^{\text {III }}$, Lessi Inês Farias Pinheiro ${ }^{\text {IV }}$.

I Universidade Estadual de Santa Cruz. erica.eal@gmail.com

II Universidade Estadual de Santa Cruz. catrine@afl.adv.br

III Universidade Estadual de Santa Cruz. ferlandaluna@hotmail.com

Iv Universidade Estadual de Santa Cruz. lifpinheiro@uesc.br 


\section{Introdução}

Em 2015, países-membros das Nações Unidas adotaram a Agenda 2030 para o Desenvolvimento Sustentável, apresentando dezessete Objetivos de Desenvolvimento Sustentável (ODS), abrangendo problemas socioeconômicos para estabelecer um caminho capaz de acabar com a pobreza, proteger o meio-ambiente e garantir a prosperidade a todos até 2030 .

Considerando o potencial das cooperativas como parte da estratégia dos Objetivos do Desenvolvimento Sustentável (ODS), a Organização das Nações Unidas (ONU) envolveu as cooperativas nesta agenda, com o objetivo de criar uma rede internacional de líderes de cooperativas, estando o Brasil dentre os 11 países participantes (PRADO, 2018).

O sistema cooperativista, apoiado nos princípios de adesão voluntária e livre, gestão democrática, participação econômica dos membros, autonomia e independência, educação formação e informação, intercooperação e interesse pela comunidade, é compreendido como instrumento de intervenção na realidade social, com foco na emancipação dos atores sociais para a conquista da cidadania. (SANTOS, 2016).

O cooperativismo constitui um sistema econômico e social capaz de promover a sustentabilidade, tanto para os seus membros, como para a comunidade em que está inserido, em virtude dos fundamentos históricos, principiológicos e organizacionais que contribuíram para o seu desenvolvimento. Segundo Glaucia Silva, o cooperativismo é um instrumento de desenvolvimento econômico, sobretudo em razão da semelhança entre os seus objetivos e os da República, destinados a viabilizar a integração social com a revitalização de valores, como solidariedade e justiça social (LEITE et al., 2013).

"O cooperativismo possibilita a estabilização e regulação econômica, social e política; acesso equitativo de bens e serviços; e diversidade e inclusão econômica, social e política; sendo estas dinâmicas principais que caracterizam o impacto socioeconômico das cooperativas" (OURO-SALIM, 2019,).

As cooperativas apresentam vantagens econômicas, sociais, morais e culturais, entendidas como a capacidade de difundir elevadas normas éticas e cooperação consciente e voluntária, democratizar e humanizar a economia, que evidenciam-se em decorrência da preservação da autonomia, dignidade pessoal e a liberdade individual dos associados, sem afetar a unidade de esforços e o trabalho comum; além de promover a formação integral do homem, através da desenvolvimento do sentido de responsabilidade, estímulo a aquisição de conhecimentos e preocupação com o bem-estar geral (PARÉ, 2010).

Sobre o tema, Schneider preleciona que as cooperativas apresentam-se como "organizações societárias vantajosas, em prol da sustentabilidade, por distribuir de forma justa e igualitária os bens e serviços que produz, permitindo a cada associado usufruir daquilo que ele ajudou a construir coletivamente e na exata proporção do seu envolvimento participativo como coproprietário e como usuário" (SCHNEIDER, 2015, 0 autor assevera ainda que a cooperativa supera a dependência e subordinação paternalista, a despeito de estruturar-se como empresa, para que seus associados, numa adequada visão de autonomia, sejam os efetivos agentes de desenvolvimento e os protagonistas, na produção qualificada e sempre maior de bens e serviços, assumindo de forma coletiva e responsável a participação e a transparência em todas as atividades de seu projeto e empreendimento coletivo e solidário (SCHNEIDER, 2015).

Com o objetivo de organizar as ações e projetos de representação das cooperativas brasileiras, a Resolução OCB no 56/2019, regulamenta a classificação do cooperativismo em sete ramos, que são: agropecuário; consumo; crédito; infraestrutura; trabalho; produção de bens e serviços; saúde; e transporte (OCB, 2019). O ramo trabalho, produção de bens e serviços, é composto por cooperativas que se destinam, precipuamente, a organizar, por meio da mutualidade, a prestação de serviços especializados a terceiros ou a produção em comum de bens (OCB, 2019). Em 2018, o ramo das 
cooperativas de trabalho congrega 925 cooperativas, que tem por objetivo principal gerar oportunidade de trabalho para 198.466 profissionais das mais diferentes áreas e ainda gerar 5.105 empregos (OCB, 2019).

Alinhado com a tendência mundial de promoção do desenvolvimento sustentável, foram desenvolvidas alterações legislativas e ações de caráter socioeconômico e socioambiental, na esfera nacional. No âmbito das licitações públicas, a Lei no 8.666/93 foi alterada pela no $12.349 / 2010$, para incluir, dentre as finalidades do procedimento licitatório, a promoção do desenvolvimento sustentável. Com isso, "as licitações não são mais encaradas como procedimentos voltados à aquisição estanque de produtos, serviços de obras, mas dotadas, também, de uma função regulatória conformadora do mercado na qual são empregados como instrumentos de implementação de políticas públicas" (GARCIA et al., 2012, Na mesma ocasião, a Lei no 8.666/93 foi alterada, para fins de impedir a criação de qualquer obstáculo à participação das cooperativas nos certames licitatórios.

A Administração Pública, ao estabelecer critérios de contratação, tem condições de influenciar na economia em todo o território nacional, em razão do seu alto poder de compra. Segundo a Organização para a Cooperação e Desenvolvimento Econômico (OCDE) ${ }^{1}$, o mercado de compras governamentais corresponde, em média, a $13 \%$ do produto interno bruto (PIB) brasileiro, mostrandose, portanto, fundamental o respeito aos princípios da isonomia e da competividade, que regem os certames licitatórios, com o fito de fortalecer o mercado interno e proporcionar o seu desenvolvimento sustentável.

Este trabalho justifica-se pela importância da produção de estudos capazes de demonstrar que, não obstante ao reconhecimento pelo legislativo do papel desempenhado pelas cooperativas em favor da sustentabilidade e da ordem econômica do país, subsistem ainda obstáculos enfrentados pelo sistema cooperativista que atrapalham seu desenvolvimento.

Não obstante o reconhecimento pelo legislativo do papel desempenhado pelas cooperativas em favor da sustentabilidade e da ordem econômica do país, o sistema cooperativista ainda enfrenta intercorrências que atrapalham o seu adequado desenvolvimento. Nesse contexto, o presente estudo tem por objetivo realizar uma análise crítica a respeito dos institutos jurídicos que tratam sobre as condições para a participação de cooperativas de trabalho em certames licitatórios, além de analisar o entendimento do Tribunal de Contas da União (TCU) a respeito da proibição da participação de cooperativas de trabalho em licitações públicas.

\section{Metodologia}

A pesquisa em questão foi constituída em um estudo descritivo e explicativo da legislação vigente que trata sobre a participação de cooperativas de trabalho em licitações públicas, realizandose também um levantamento de acórdãos do Tribunal de Contas da União (TCU) que relacionam os temas cooperativas e licitação. Para Gil (2007), "uma pesquisa explicativa pode ser a continuação de outra descritiva, posto que a identificação de fatores que determinam um fenômeno exige que este esteja suficientemente descrito e detalhado".

Para alcance dos objetivos deste estudo, realizou-se uma análise documental que permitiu a descrição das disposições normativas vigentes relacionadas ao tema escopo deste trabalho, efetuandose também um estudo explicativo, preocupando-se em identificar os fatores que determinam ou que contribuem para a ocorrência dos fenômenos (GIL,2010). Assim, através da demonstração da relevância do contexto em que as cooperativas de trabalho estão inseridas, por configurarem meio de promoção do desenvolvimento nacional sustentável reconhecido inclusive pela agenda 2030, buscouse apresentar os fatores legislativos e conjunturais que podem contribuir para uma melhor interpretação sobre as normas que versam sobre a participação de cooperativas nos procedimentos licitatórios.

1 Disponível em: http://www.fnde.gov.br/acoes/compras-governamentais/sobre-compras-governamentais. Acesso em: 7 jun 2019. 


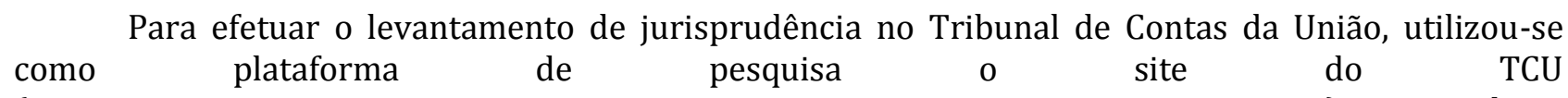
(https://pesquisa.apps.tcu.gov.br/\#/pesquisa/jurisprudencia-selecionada), servindo-se dos seguintes filtros de pesquisa disponibilizados na plataforma eletrônica de consulta: "pesquisa de jurisprudência selecionada"; "pesquisa pela árvore de classificação"; "área licitação"; "tema cooperativa"; "subtema vedação".

Através do acesso ao sítio eletrônico mencionado, seguindo a orientação dos filtros disponibilizados, encontrou-se publicados 12 acórdãos e 01 súmula no período indicado. 0 período utilizado como referência para a pesquisa jurisprudencial foi entre os anos de 2003 e 2019, sendo analisadas aquelas que se enquadram no escopo do estudo.

A partir da análise dos referidos acórdãos, identificou-se os fundamentos jurídicos admitidos pelo Tribunal de Contas da União para a participação de cooperativas de trabalho em licitações públicas.

\section{Súmula 281 TCU e demais entraves jurídicos para a participação de cooperativas de trabalho em licitações públicas}

O parágrafo único do artigo 442 da CLT estabelece que "qualquer que seja o ramo de atividade da sociedade cooperativa, não existe vínculo empregatício entre ela e seus associados, nem entre estes e os tomadores de serviços daquela" 2 . Apesar da conformidade desta norma com as regras e princípios básicos do cooperativismo, sobretudo no que tange à ausência de subordinação entre a cooperativa e o cooperado, esta se tornou alvo de interpretações equivocadas, de modo a contribuir para a propagação de cooperativas fraudulentas, criadas unicamente com o intuito de burlar a legislação trabalhista.

No que se refere à responsabilidade do tomador de serviço, a Súmula 331 do TST estabelecia que este respondesse de forma subsidiária pelo inadimplemento das obrigações trabalhistas, inclusive quanto aos órgãos da Administração Pública ${ }^{3}$. Com isso, ao contratar com cooperativas, a Administração Pública sujeitava-se ao risco de arcar com dívidas trabalhistas de terceiros, e, consequentemente, comprometer a vantajosidade da contratação, além de causar dano ao erário.

Nesse contexto, a proibição de participação de cooperativas de trabalho em licitações públicas federais adquiriu suporte jurídico com a homologação do Termo de Conciliação Judicial firmado entre o Ministério Público do Trabalho (MPT) e a União, em 2003, nos autos da Ação Civil Pública proposta perante a 20 a Vara do Trabalho de Brasília (Processo 01082-2002-020-10-00-00). 0 objetivo consistia justamente em coibir a responsabilização da Administração Pública por atos praticados por cooperativas fraudulentas. Dentre as justificativas apresentadas para a emissão do documento, há menção para a existência de "trabalhadores aliciados por cooperativas de mão-de-obra", que, ao prestarem serviços terceirizáveis, são privados das normas de proteção jurídico laboral. Contém, ainda, listagem de serviços cuja contratação é vedada pela União, sob pena de incidência de multa, conforme detalhamento a seguir:

Cláusula Primeira - A UNIÃo abster-se-á de contratar trabalhadores, por meio de cooperativas de mãode-obra, para a prestação de serviços ligados às suas atividades-fim ou meio, quando o labor, por sua própria natureza, demandar execução em estado de subordinação, quer em relação ao tomador, ou em relação ao

\footnotetext{
${ }^{2}$ Incluído pela Lei no 8.949 , de 9.12.1994.

${ }^{3}$ Enunciado Súmula 331 TST, item IV - 0 inadimplemento das obrigações trabalhistas, por parte do empregador, implica na responsabilidade subsidiária do tomador dos serviços, quanto àquelas obrigações, inclusive quanto aos órgãos da administração direta, das autarquias, das fundações públicas, das empresas públicas e das sociedades de economia mista, desde que hajam participado da relação processual e constem também do título executivo judicial (artigo 71 da Lei n. 8.666/93) (BRASIL, 2000).
} 
fornecedor dos serviços, constituindo elemento essencial ao desenvolvimento e à prestação dos serviços terceirizados, sendo eles:

a) - Serviços de limpeza;

b) - Serviços de conservação;

c) - Serviços de segurança, de vigilância e de portaria;

d) - Serviços de recepção;

e) - Serviços de copeiragem;

f) - Serviços de reprografia;

g) - Serviços de telefonia;

h) - Serviços de manutenção de prédios, de equipamentos, de veículos e de instalações;

i) - Serviços de secretariado e secretariado executivo;

j) - Serviços de auxiliar de escritório;

k) - Serviços de auxiliar administrativo;

l) - Serviços de office boy (contínuo);

m) - Serviços de digitação;

n) - Serviços de assessoria de imprensa e de relações públicas;

o) - Serviços de motorista, no caso de os veículos serem fornecidos pelo próprio órgão licitante;

p) - Serviços de ascensorista;

q) - Serviços de enfermagem; e

r) - Serviços de agentes comunitários de saúde.

Seguindo o entendimento endossado pelo Termo de Conciliação Judicial, a Secretaria de Logística e Tecnologia da Informação do Ministério do Planejamento, Orçamento e Gestão publicou a Instrução Normativa 2/2008, que apesar de autorizar a contratação de cooperativas pela Administração Pública, estabelece limitações em razão da natureza do serviço. Nos termos do artigo 4ํㅜ a contração de sociedades cooperativas somente poderá ocorrer mediante a demonstração da ausência de subordinação entre a cooperativa e os cooperados; entre a Administração e os cooperados; além da possibilidade de gestão operacional do serviço compartilhada ou em rodízio.

No mesmo sentido, 0 Tribunal de Contas da União, em 2012, publicou a Súmula TCU 281, vigente, nos seguintes termos:

É vedada a participação de cooperativas em licitação quando, pela natureza do serviço ou pelo modo como é usualmente executado no mercado em geral, houver necessidade de subordinação jurídica entre o obreiro e o contratado, bem como de pessoalidade e habitualidade.

Historicamente, o Tribunal de Contas da União manteve posicionamento firme a favor da restrição de contratação das cooperativas pela Administração Pública, quando houver qualquer indício de subordinação, habitualidade e pessoalidade, entre os serviços prestados pelos cooperados à cooperativa, o que, de certo modo, representaria risco para o erário ${ }^{4}$.

Apesar da patente necessidade de combater a atuação das cooperativas fraudulentas, questiona-se a constitucionalidade e a legalidade das medidas até então adotadas pelo Ministério Público do Trabalho e pelos órgãos de controle. É que a Constituição Federal de 1988 considera o cooperativismo como sistema fundamental para o desenvolvimento da atividade econômica do país, assegurando-o em várias passagens, como é o caso do inciso XVIII do artigo 5ㅜㅜ, que trata da independência no que tange à criação de cooperativas e ainda à liberdade em seu funcionamento; o inciso III, c, do art. 146, que determina o adequado tratamento tributário ao ato cooperativo; o $\S 2^{\circ}$ do

\footnotetext{
${ }^{4}$ Acórdão 5736/2011-Primeira Câmara TCU - Enunciado: Não há óbice à participação de cooperativas nas licitações, contudo, a contratação dessas entidades pela Administração Pública deve subordinar-se aos comandos do Termo de Conciliação Judicial celebrado, em 5/6/2003, entre o Ministério Público do Trabalho e a Advocacia Geral da União e os serviços licitados devem ser prestados em caráter coletivo e com absoluta autonomia dos cooperados, sem que haja relação de subordinação entre os associados e o tomador dos serviços. Demais Precedentes: Acórdão no 975/2005- Segunda Câmara; Acórdão no 724/2006 - Plenário; Acórdão no 2172/2005 Plenário; Acórdão no 1815/2003 - Plenário; Acórdão no 23/2003 - Plenário; e Acórdão no 22/2003 - Plenário.
} 
art. 174, que determina a edição de lei para estimular e apoiar o cooperativismo, nos termos a seguir transcrito:

Art. 5o, da CRFB/1988: Todos são iguais perante a lei, sem distinção de qualquer natureza, garantindo-se aos brasileiros e aos estrangeiros residentes no País a inviolabilidade do direito à vida, à liberdade, à igualdade, à segurança e à propriedade, nos termos seguintes: [...] XVIII - a criação de associações e, na forma da lei, a de cooperativas independem de autorização, sendo vedada a interferência estatal em seu funcionamento. [...]

Art. 146, da CRFB/1988: Cabe à lei complementar: [...] III - estabelecer normas gerais em matéria de legislação tributária, especialmente sobre: [...] c) adequado tratamento tributário ao ato cooperativo praticado pelas sociedades cooperativas. [...]

Art. 174, da CRFB/1988: Como agente normativo e regulador da atividade econômica, o Estado exercerá, na forma da lei, as funções de fiscalização, incentivo e planejamento, sendo este determinante para o setor público e indicativo para o setor privado. [...] § $2^{\mathrm{o}}$ A lei apoiará e estimulará o cooperativismo e outras formas de associativismo.

A respeito do tema, Glaucia Silva enfatiza o seguinte:

Não se pode deixar de frisar que é nítido o reconhecimento por parte do legislador constituinte, da potencialidade do cooperativismo como agente capaz de contribuir para o desenvolvimento brasileiro, e tal, decorre da nítida identificação de princípios, ou seja a Constituição Federal encontra neste sistema, os elementos necessários para a consecução do seu objetivo maior que é o desenvolvimento da nação, eis que possui em seu ideário atributos que se lhe amoldam (LEITE et al, 2013, p. 7).

No âmbito infralegal, destaca-se o caráter competitivo dos certames licitatórios, que veda aos agentes públicos a realização de distinções ou restrições com base em circunstâncias impertinentes ou irrelevantes para o específico objeto do contrato ${ }^{5}$. Carvalho Filho (2013) assevera que a igualdade de oportunidades a todos que se interessam em contratar com a Administração constitui um dos fundamentos essenciais ao próprio instituto da licitação, ressaltando que esse fundamento envolve os princípios da igualdade e da impessoalidade, de obrigatória observância por todos aqueles que integram os quadros da Administração (CARVALHO FILHO, 2013,).

Assim, o Termo de Conciliação Judicial firmado entre o MPT e a União em 2003 e a Súmula TCU 281 apresentam, desde o surgimento no ordenamento jurídico brasileiro, vícios suficientes para afastar à aplicação no caso concreto. No entanto, ao analisar a jurisprudência do Superior Tribunal de Justiça (STJ) ${ }^{6}$, observa-se a concordância com a vedação à participação de cooperativas de trabalho em licitações públicas, sem qualquer aprofundamento ou interpretação crítica acerca das nuances que giram em torno da matéria. Ao aquiescer com as restrições infundadas ora discutidas, o STJ direciona os demais entes da Administração Pública direta e indireta a adotar o mesmo posicionamento, inicialmente formulado para a Administração Pública Federal, o que agrava ainda mais a situação das cooperativas, ante o impedimento de contratar com a Administração Pública, com patente violação à autonomia do cooperativismo e a livre concorrência.

\footnotetext{
${ }^{5}$ Art. $3^{\circ}$,,$~ 1^{\circ}$, I da Lei 8.666/1993.

${ }^{6}$ ADMINISTRATIVO - LICITAÇÃO - PRESTAÇÃO DE SERVIÇOS COM LOCAÇÃO DE MÃO DE OBRA - VEDAÇÃO À PARTICIPAÇÃO DE COOPERATIVAS - RAZOABILIDADE DA EXIGÊNCIA EDITALÍCIA - INEXISTÊNCIA DE ILEGALIDADE. 1. É fato público e notório que a legislação trabalhista e previdenciária é implacável com os tomadores de serviço, atribuindo-lhes, inclusive, a condição de responsáveis pelo pagamento de salários e tributos não recolhidos. 2. A Corte Especial pacificou entendimento segundo o qual é inadmissível a participação de cooperativas em processos licitatórios para contratação de mão de obra quando o labor, por sua natureza, demandar necessidade de subordinação, ante os prejuízos que podem advir para a Administração Pública caso o ente cooperativo se consagre vencedor no certame e não cumpra suas obrigações. Precedentes. 3. Recurso especial provido. (REsp 1204186/RS, Rel. Ministra ELIANA CALMON, SEGUNDA TURMA, julgado em 18/10/2012, DJe 29/10/2012)
} 
Ao vedar, indistintamente, a possibilidade de contratação de cooperativas de trabalho pela Administração Pública, mesmo às legalmente construídas e comprovadamente regular com todas as suas obrigações, com base apenas na natureza do serviço prestado, além de violar os preceitos legais mencionados, ocorre a significativa redução das possibilidades de crescimento no âmbito nacional de um sistema altamente viável, sustentável, que busca a eliminação da exploração das forças de trabalho. A problemática consiste em atribuir as mesmas consequências jurídicas para as cooperativas que atuam de maneira fraudulenta e para as cooperativas que atuam em conformidade com a legislação vigente.

Ressalte-se que a Lei Geral de Licitações prescreve o dever legal de fiscalização da execução dos contratos, cabendo à Administração Pública verificar a adoção de práticas abusivas ou fraudulentas, praticadas por qualquer contratada, independente da natureza da pessoa jurídica, se sociedade de capital ou sociedade de pessoas, conforme dispõe o artigo 67:

Artigo 67, Lei 8.666/93: A execução do contrato deverá ser acompanhada e fiscalizada por um representante da Administração especialmente designado, permitida a contratação de terceiros para assisti-lo e subsidiá-lo de informações pertinentes a essa atribuição.

Carvalho (2016), explica que a fiscalização da execução dos contratos constitui um poderdever da administração pública (CARVALHO, 2016). Trata-se, portanto, de instituto jurídico hábil para fins de coibir práticas abusivas e fraudulentas, o que evidencia o caráter desarrazoado de normas que rotulam, a priori, toda e qualquer cooperativa que preste determinados tipos de serviço como fraudulenta, aplicando-lhes sansões que afetam o próprio exercício da atividade econômica, o que desencadeia consequências negativas, tanto no aspecto microeconômico, quanto macroeconômico, dada a importância do seguimento para o desempenho da atividade produtiva do país.

Se a fundamentação jurídica para a proibição da participação de cooperativas em licitações públicas já nasceu revestida de incongruências e ilegalidades, como dito, por maior razão, desde 2010, não subsiste qualquer justificativa plausível para a subsistência no ordenamento jurídico vigente dos preceitos contidos no Termo de Conciliação Judicial firmado entre o MPT e na União em 2003 e a Súmula TCU 281, em decorrência de importâncias alterações legislativas, que tratam de temas relacionados à sustentabilidade, compras públicas e cooperativismo, cuja contextualização e detalhamento será apresentado no tópico seguinte.

\section{Novo regramento jurídico para a contratação de cooperativas de trabalho pela Administração Pública}

Recentemente, a Organização das Nações Unidas (ONU) reafirmou o apoio aos 17 Objetivos de Desenvolvimento Sustentável (ODS), propostos por um grupo de trabalho de Estados membros para a nova agenda que o Fórum Mundial aplicará entre 2015 e 20307. Os 17 ODS incluem vários problemas socioeconômicos, como pobreza, fome, igualdade de gênero, industrialização, desenvolvimento sustentável, pleno emprego, educação de qualidade, mudança climática e energia sustentável para todos.

Alinhados a essa perspectiva, as cooperativas surgem como importante pilar do setor privado para contribuir com a erradicação da pobreza e o desenvolvimento econômico, através da realização de práticas sustentáveis.

A partir desse cenário, no qual as cooperativas apresentam exponencial visibilidade na promoção dos objetivos encartados pela Organização das Nações Unidas, surge a plataforma Coops $^{8}$ for 2030, que objetiva fomentar as propostas da agenda e realinhar tais objetivos com as cooperativas que comungam desse mesmo propósito. Para isso, a Plataforma disponibilizou um documento intitulado

\footnotetext{
${ }^{7}$ Disponível em: http://www.agenda2030.com.br/. Acesso em: 07.jun. 2019.

${ }^{8}$ Disponível em: http://www.coopsfor2030.coop/pt/about. Acesso em 27 abr. 2020.
} 
de Blueprint for a Co-operative Decade (Plano para uma Década Cooperativa) ${ }^{9}$, no qual destrincha um plano de ação para que as cooperativas se adequem a proposta do desenvolvimento sustentável até o ano de 2030, abarcando em seu cerne temas como, participação, sustentabilidade, identidade, enquadramento legal e capital.

Vinculado a esta ótica, Schneider apregoa que as cooperativas apresentam-se como organizações societárias vantajosas, em prol da sustentabilidade, por distribuir de forma justa e igualitária os bens e serviços que produz, permitindo a cada associado usufruir daquilo que ele ajudou a construir coletivamente e na exata proporção do seu envolvimento participativo como coproprietário e como usuário (SCHNEIDER, 2015).

A partir de tais inferências, as cooperativas podem direcionar as suas atividades fincadas nas premissas do desenvolvimento sustentável e estabelecê-las frente ao mercado, através de práticas sustentáveis, elencadas por Schneider (2015), nos seguintes termos:

\begin{abstract}
Exploração dos recursos vegetais de florestas e matas de forma controlada, garantindo o replantio sempre que necessário; Preservação total de áreas verdes não destinadas à exploração econômica; Ações que visem ao incentivo à produção e consumo de alimentos orgânicos, pois estes não agridem a natureza além de serem benéficos à saúde dos seres humanos; Exploração dos recursos minerais (petróleo, carvão, minérios) de forma controlada, racionalizada e com planejamento; Uso de fontes de energia limpas e renováveis (eólica, geotérmica e hidráulica) para diminuir o consumo de combustíveis fósseis; Esta ação, além de preservar as reservas de recursos minerais, visa diminuir a poluição do ar; Criação de atitudes pessoais e empresariais voltadas para a reciclagem de resíduos sólidos. Esta ação, além de gerar renda e diminuir a quantidade de lixo no solo, possibilita a diminuição da retirada de recursos minerais do solo; Desenvolvimento da gestão sustentável nas empresas para diminuir o desperdício de matéria-prima e o desenvolvimento de produtos com baixo consumo de energia; Atitudes voltadas para o consumo controlado de água, evitando ao máximo o desperdício; Adoção de medidas que visem à não poluição dos recursos hídricos, assim como a despoluição daqueles que se encontram poluídos ou contaminados.
\end{abstract}

A partir de tais instruções, resta evidenciado como as atividades realizadas pelas cooperativas comprometidas com o desenvolvimento sustentável, podem crescer no seu segmento sem comprometer os recursos naturais disponíveis para as gerações presente e as que estão por vir.

Em tal medida, Schneider (2015), imbuído dessa perspectiva de que os negócios desenvolvidos pelas cooperativas podem maximizar o crescimento econômico sem afastar os ditames ambientais, colaciona as vantagens de aderir a esta conjura nos seguintes contextos: o uso equitativo e distribuição para aqueles que participaram da produção; atuação democrática dos componentes nas ações decisórias; a produção não apenas apara atender ao mercado consumidor, mas também ao bem estar daqueles que estão nas esferas produtivas; compartilhamento e preservação da individualidade dos cooperados; evolucionista do desenvolvimento, identidade e humanidade, como característica que diferencia dos demais negócios; participação do indivíduo enquanto cidadão, promovendo o exercício deste enquanto protagonista para o desenvolvimento social.

Seguindo a tendência mundial que visa promover o desenvolvimento sustentável, importantes alterações legislativas e ações de caráter socioeconômico e socioambiental, foram implementadas na esfera nacional no âmbito das licitações públicas. Neste esteio, a Lei no 8.666/93 foi alterada pela Lei no $12.349 / 2010$, para incluir, dentre as finalidades do procedimento licitatório, a promoção do desenvolvimento nacional sustentável. $\mathrm{Na}$ mesma ocasião, foi reforçado o princípio da competitividade, com alusão expressa à proibição de condições que restrinjam ou frustrem o caráter competitivo dos certames licitatórios, inclusive nos casos de sociedades cooperativas, conforme transcrição a seguir:

9 Disponível em: https://www.ica.coop/sites/default/files/publication-files/ica-blueprint-final-june-2013-portuguese975329096.pdf. Acesso em 27 abr 2020. 
Art. 3ำ A licitação destina-se a garantir a observância do princípio constitucional da isonomia, a seleção da proposta mais vantajosa para a administração e a promoção do desenvolvimento nacional sustentável e será processada e julgada em estrita conformidade com os princípios básicos da legalidade, da impessoalidade, da moralidade, da igualdade, da publicidade, da probidade administrativa, da vinculação ao instrumento convocatório, do julgamento objetivo e dos que lhes são correlatos. $\S 1^{\text {o }}$ É vedado aos agentes públicos:

I - admitir, prever, incluir ou tolerar, nos atos de convocação, cláusulas ou condições que comprometam, restrinjam ou frustrem o seu caráter competitivo, inclusive nos casos de sociedades cooperativas, e estabeleçam preferências ou distinções em razão da naturalidade, da sede ou domicílio dos licitantes ou de qualquer outra circunstância impertinente ou irrelevante para o específico objeto do contrato, ressalvado o disposto nos $\S \S 5^{\circ}$ a 12 deste artigo e no art. 3ํㅡ da Lei no 8.248, de 23 de outubro de 1991.

O legislador teve o intuito de reestabelecer a ordem constitucional, que consagra a cooperativa como organização econômica capaz de promover o desenvolvimento sustentável. Na exposição de motivos, há referência ao artigo 219 da Constituição Federal de 1988, que trata de incentivos ao mercado interno, de forma a viabilizar o desenvolvimento cultural e socioeconômico, o bem estar da população e a autonomia tecnológica do país.

Com a edição da Lei no 12.690/2012, que dispõe sobre a organização e o funcionamento das Cooperativas de Trabalho e institui o Programa Nacional de Fomento às Cooperativas de Trabalho PRONACOOP, o legislador contribuiu para o fortalecimento da identidade jurídica das cooperativas de trabalho, cuja atuação baseia-se em princípios básicos do cooperativismo, tais como, a adesão voluntária e livre; gestão democrática; participação econômica dos membros; autonomia e independência; educação, formação e informação; intercooperação; interesse pela comunidade; preservação dos direitos sociais, do valor social do trabalho e da livre iniciativa; não precarização do trabalho, respeito às decisões de assembleia, participação na gestão e todos os níveis de decisão e de acordo com o previsto na lei no estatuto social.

0 artigo $2^{\circ}$ da Lei 12.690/2012 conceitua as cooperativas de trabalho como a sociedade constituída por trabalhadores para o exercício de suas atividades laborativas ou profissionais com proveito comum, autonomia e autogestão para obterem melhor qualificação, renda, situação socioeconômica e condições gerais de trabalho. Nesse ponto, destaca-se que a "cooperativa de trabalho" não se confunde e não se relaciona com a dita "cooperativa de intermediação de mão-deobra", termo este pejorativo, comumente utilizado para caracterizar as cooperativas fraudulentas, cuja relação de seus membros se confunde com as relações de emprego, devida a presença de subordinação, além da frequente sonegação de direitos trabalhistas, conexos com a própria dignidade da pessoa humana.

As cooperativas de trabalho, nos termos da Lei no Lei 12.690/2012, artigo 4ํㅡ, são classificadas em cooperativas de produção e de serviços. São consideradas cooperativas de produção aquelas em que sócios que contribuem com trabalho para a produção em comum de bens e a cooperativa detém, a qualquer título, os meios de produção; enquanto que as cooperativas de serviços são constituídas para a prestação de serviços especializados a terceiros, sem a presença dos pressupostos da relação de emprego.

A exposição de motivos do Projeto de Lei no 7009/2006, que resultou na Lei no $12.690 / 2012$, enfatiza o intuito de combater a utilização do sistema cooperativista para a prática de condutas abusivas, conforme se observa no trecho a seguir transcrito:

6. A presente proposta visa a coibir as fraudes, vedando, terminantemente, a intermediação de mão-de-obra sob o subterfúgio das cooperativas de trabalho. Esta prática abusiva vem se revelando como meio degradante de prestação de trabalho, uma vez que o trabalhador presta serviços em condições próprias de emprego, privado dos direitos reconhecidos pela Constituição Federal e pela legislação trabalhista. 
7. Estas cooperativas de intermediação de mão-de-obra apresentam mera aparência de cooperativas, uma vez, não obstante formalizem-se como tal, obedecendo aos requisitos legais para tanto, substancialmente não o são, pois o trabalhador "cooperado" que presta serviços pessoais e subordinados a terceiros, nada mais é, senão empregado. Sua força de trabalho transfere lucro aos tomadores, o que é compatível com o vínculo de emprego, mas não com o cooperativismo. Trata-se, portanto, de emprego precário, porque não protegido pelos direitos sociais que lhe seriam inerentes.

A supracitada norma possibilitou, ainda, a eliminação de qualquer controvérsia existente a respeito da relação jurídica estabelecida entre a cooperativa e o cooperado, ao esclarecer que a Cooperativa de Trabalho não pode ser utilizada para intermediação de mão de obra subordinada, além de garantir os seguintes direitos para o cooperado:

Art. 7ํ A Cooperativa de Trabalho deve garantir aos sócios os seguintes direitos, além de outros que a Assembleia Geral venha a instituir:

I - retiradas não inferiores ao piso da categoria profissional e, na ausência deste, não inferiores ao salário mínimo, calculadas de forma proporcional às horas trabalhadas ou às atividades desenvolvidas;

II - duração do trabalho normal não superior a 8 (oito) horas diárias e 44 (quarenta e quatro) horas semanais, exceto quando a atividade, por sua natureza, demandar a prestação de trabalho por meio de plantões ou escalas, facultada a compensação de horários;

III - repouso semanal remunerado, preferencialmente aos domingos;

IV - repouso anual remunerado;

$\mathrm{V}$ - retirada para o trabalho noturno superior à do diurno;

VI - adicional sobre a retirada para as atividades insalubres ou perigosas;

VII - seguro de acidente de trabalho.

$\S 1$ ํo Não se aplica o disposto nos incisos III e IV do caput deste artigo nos casos em que as operações entre o sócio e a cooperativa sejam eventuais, salvo decisão assemblear em contrário ${ }^{10}$.

Percebe-se que os direitos garantidos aos cooperados se assemelham com os direitos trabalhistas esculpidos no artigo 7ํㅜ da Constituição Federal de 1988. A nova lei também prevê que a constituição ou utilização de Cooperativa de Trabalho para realização de práticas ilícitas ou fraudulentas acarretará aos responsáveis as sanções penais, cíveis e administrativas cabíveis.

No que tange à possibilidade de participação de cooperativas em licitações públicas, o artigo 10 estabelece que a cooperativa poderá adotar qualquer gênero de serviço, operação ou atividade, sendolhe garantida o direito de participar de certames licitatórios quando o objeto licitado for compatível com o seu objeto social, nos termos abaixo delineados:

Art. 10. A Cooperativa de Trabalho poderá adotar por objeto social qualquer gênero de serviço, operação ou atividade, desde que previsto no seu Estatuto Social.

$\S 1$ 1o É obrigatório o uso da expressão "Cooperativa de Trabalho" na denominação social da cooperativa.

$\S 2^{2}$ A Cooperativa de Trabalho não poderá ser impedida de participar de procedimentos de licitação pública que tenham por escopo os mesmos serviços, operações e atividades previstas em seu objeto social ${ }^{11}$.

A Lei das Cooperativas de Trabalho introduziu no ordenamento jurídico a função do coordenador de cooperativas ${ }^{12}$, responsável pelo acompanhamento das atividades desenvolvidas fora

${ }^{10}$ Lei no $12.690 / 2012$, artigo $7^{\circ}$, caput e $\S 1^{\circ}$.

${ }^{11}$ Lei no $12.690 / 2012$, artigo 10 , § $2^{\circ}$.

12 Lei no 12.690/2012, artigo 7으, § 6을 As atividades identificadas com o objeto social da Cooperativa de Trabalho prevista no inciso II do caput do art. 40 desta Lei, quando prestadas fora do estabelecimento da cooperativa, deverão ser submetidas a uma coordenação com mandato nunca superior a 1 (um) ano ou ao prazo estipulado para a realização dessas atividades, eleita em reunião específica pelos sócios que se disponham a realizá-las, em 
do estabelecimento da cooperativa, o que afasta a possibilidade de subordinação entre o tomador dos serviços e o cooperado, além de atribuir maior segurança jurídica para as partes envolvidas na contratação.

Merece destaque, ainda, o julgamento anterior pelo STF da ADC 16, com consequente alteração do item IV e inclusão do item V no Enunciado da Súmula 331 do TST ${ }^{13}$, para fins de constar que a Administração Pública direta e indireta, enquanto tomadora de serviços, somente responderá pelo inadimplemento das obrigações trabalhistas por parte do empregador, quando evidenciada a sua conduta culposa no cumprimento das obrigações da Lei n.o 8.666/1993, especialmente na fiscalização do cumprimento das obrigações contratuais e legais da prestadora de serviço como empregadora. Nesse sentido, a responsabilidade não decorre de mero inadimplemento das obrigações trabalhistas assumidas pela empresa contratada, como ocorria anteriormente, nos termos da antiga redação do item IV, da Súmula 331 TST, citada alhures, o que reduz significativamente o risco para a Administração Pública, resultante da contratação de serviços terceirizados.

Dessa forma, A Lei no 12.349/2010, que alterou o artigo $3^{\text {a }}$ da Lei $n^{\circ}$ 8.666/93, e a Lei $n^{\circ}$ $12.690 / 2012$, juntas, representam o novo regramento jurídico para a contratação de cooperativas de trabalho pela Administração Pública, ao enfatizar no ordenamento jurídico brasileiro a concepção da cooperativa como instrumento socioeconômico hábil para a promoção do desenvolvimento nacional sustentável, além de inserir regulamentação detalhada sobre as Cooperativas de Trabalho, que, inclusive, ensejou a revogação do parágrafo único do artigo 442 da Consolidação das Leis do Trabalho (CLT).

A Secretaria de Logística e Tecnologia da Informação do Ministério do Planejamento, Orçamento e Gestão publicou a Instrução Normativa 5/2017, que revogou a Instrução Normativa 2/2008 e estabeleceu novas regras para a contratação de cooperativas pela Administração Pública Federal, com o intuito de se adequar ao regramento contido no Programa Nacional de Fomento às Cooperativas de Trabalho - PRONACOOP. A Instrução Normativa 5/2017 mantém a proibição de contratação de cooperativas pela Administração Pública Federal quando a natureza do serviço indicar a possibilidade de subordinação entre a cooperativa e os cooperativos, no entanto, inova ao admitir a participação das cooperativas nos certames licitatórios mediante apresentação de um modelo de gestão operacional, que evidencie a adequação da atuação da cooperativa com as normas e princípios que tratam da matéria.

A apresentação do modelo de gestão operacional exigido para as cooperativas interessadas em participar dos certames licitatórios corresponde a uma ferramenta que, ao mesmo tempo, garante o exercício do direito das cooperativas de concorreram em igualdade de condições com os demais licitantes; e atribui segurança para a Administração Pública.

A proibição de contratação de cooperativos que prestem os serviços elencados pela Cláusula Primeira do Termo de Conciliação Judicial firmado entre o MPT e a União em 2003, conflita sobremaneira com a regulamentação contida no artigo 10 da Lei no $12.690 / 2012$. Nesse sentido, Gusmão enfatiza:

Percebe-se que a Lei 12.690/12 gerou verdadeira virada de Copérnico no tratamento jurídico das cooperativas, com a necessária reformulação de todos os paradigmas que deram ensejo à assinatura do Termo de Conciliação, em grande medida pelo fato de a nova normatização ter trazido uma série de direitos aos cooperados que antes lhes eram negados, permitindo que as verdadeiras cooperativas possam fornecer serviços de qualidade, com cooperados qualificados, que participam da gestão coletiva da instituição de maneira democrática, e que possuem direitos à semelhança dos direitos garantidos aos trabalhadores em geral (GUSMÃO, 2014. p. 9).

que serão expostos os requisitos para sua consecução, os valores contratados e a retribuição pecuniária de cada sócio partícipe.

13 Precedentes: nova redação do item IV e inseridos os itens V e VI à redação - Res. 174/2011, DEJT divulgado em 27,30 e 31.05 .2011$. 
0 posicionamento ora defendido consiste no afastamento de toda e qualquer norma de proibição de participação de cooperativas de trabalho em licitações públicas, em razão da incompatibilidade destas com o novo regramento jurídico implementado. Sobre o tema, Gusmão assevera a necessidade de buscar na nova normatização sua máxima eficácia, garantindo que o novo seja implementado, e a ordem anterior seja considerada superada, afastando a síndrome da interpretação retrospectiva das leis (GUSMÃO, 2014.). E Explica:

Não cabe sustentar que as normas trazidas pelas Leis 12.690/2012 e 12.349/2010 em nada inovaram e que cumpre manter a anterior interpretação sobre o regime jurídico das cooperativas, com a manutenção de todas as vedações trazidas pelo Termo de Conciliação Judicial firmado entre o MPT e a União. Diante da Lei 12.690/12, o Termo de Conciliação celebrado entre o MPT e a União em 2003 não pode mais prevalecer, merecendo uma leitura à luz do novo quadro normativo instaurado (GUSMÃo, 2014, loc cit.).

O Autor pontua que uma vez constatada a alteração do quadro normativo que conferia base para o citado Termo de Conciliação Judicial, não há que se falar em violação à coisa julgada pela aplicação da Lei no 12.690/12 para as novas licitações deflagradas a partir da vigência da nova legislação, por se tratar de relação jurídica continuativa, mutável no prolongamento do tempo, que traz em si, implicitamente, a cláusula rebus sic standibus (GUSMÃO, 2014

A despeito da clareza dos argumentos apresentados, suficientes, inclusive, para ensejar o afastamento da Súmula TCU 281, o que se observa, na prática, é a resistência dos órgãos de controle para admitir a realização dos certames licitatórios em conformidade com este novo paradigma jurídico. Em julgados recentes, o Tribunal de Contas da União ratificou o entendimento, segundo o qual, é irregular a participação de cooperativas em licitação cujo objeto se refira a prestação de serviço que demande requisitos próprios da relação de emprego, como subordinação (hierarquia) e habitualidade (jornada de trabalho) dos trabalhadores ${ }^{14}$, por suposta violação dos artigos $4^{\circ}$, inciso II, e $5^{\circ}$ da Lei no 12.690/2012, a Súmula TCU 281, o Termo de Conciliação Judicial entre a União e o Ministério Público do Trabalho, de 5/6/2003, e o artigo 4o da IN-SLTI/MPOG 2/200815.

O equívoco consiste em impedir a participação de cooperativas em licitações públicas, em razão apenas da natureza do serviço prestado, com fulcro na Lei no 12.690/2012, quando o próprio diploma legal indicado para justificar a decisão proferida no acórdão, permite a adoção de qualquer objeto social pelas cooperativas de trabalho, permite a jornada de trabalho não superior a 44 horas semanais, e prevê mecanismos para impedir eventual subordinação entre o tomador de serviços e o cooperado, como o acompanhamento efetuado pelo coordenador de cooperativas.

Recentemente, o Ministro Bruno Dantas reacendeu o debate jurídico sobre o tema no âmbito do Tribunal de Contas da União, ao posicionar-se contra a restrição à participação de cooperativas nos certames licitatórios, com base apenas na natureza jurídica do serviço prestado, ante o comando constitucional de estímulo ao cooperativismo, amparado palas Leis no 12.349/2010 e 12.690/2012, conforme trecho do julgado a seguir transcrito ${ }^{16}$ :

57. Observe-se que a nossa constituição, fundamento maior do nosso sistema jurídico, estabelece o apoio ao cooperativismo. Dessa forma, seria contraditório estipular como regra, na contratação por órgãos públicos, a vedação de participação de cooperativas. 58. Anoto que não se está aqui a defender que se autorize a utilização de cooperativas para burlar as leis trabalhistas. Isso inegavelmente deve ser combatido. 0 que questiono é a forma de combater-se tal utilização. A meu ver, não se sustenta legalmente, para tal fim, impedir cooperativas de participar de certames públicos. $[\ldots]$

\footnotetext{
${ }^{14}$ Acórdão 2221/2013-Plenário.

15 Acórdão 2260/2017-Primeira Câmara.

${ }^{16}$ Acórdão 2463/2019-Primeira Câmara.
} 
65. Portanto, o contexto em que foi assinado o Termo de Conciliação entre o Ministério Público do Trabalho e a União, bem como em que se proferiram os precedentes que embasaram a Súmula TCU 281, é bem diferente do atual. Naquela época, o risco de utilização de cooperativas como meio de burlar a legislação trabalhista era bem maior, o que, de certa forma, justificava a vedação de contratação desse tipo de associação para a execução de determinados serviços típicos de relação empregatícia.

66. Com a edição da lei, todavia, a preocupação que deve exercer o ente público federal não é com a natureza do serviço a ser contratado, mas com a inidoneidade da cooperativa. 0 órgão ou entidade pública deverá certificar-se quanto à regularidade de tais sociedades e à relação mantida com seus cooperados, além de exigir a prestação do serviço de forma coordenada, nos termos do $\operatorname{art.} 7^{\circ}$, $§ 6^{\circ}$, da referida norma.

Em consonância com o posicionamento do Ministro Relator, firmou-se entendimento no Acórdão 2463/2019-Primeira Câmara - TCU, segundo o qual, a vedação à participação de cooperativas em licitação não deve levar em conta a natureza do serviço a ser contratado, sob pena de violação do art. 10 da Lei 12.690/2012, o qual admite a prestação, pelas cooperativas, de qualquer gênero de serviço, operação ou atividade, desde que prevista em seu objeto social. Oportunamente, os autos foram encaminhados à Comissão de Jurisprudência da Corte, para que avalie a conveniência e a oportunidade de revisitar o entendimento proferido na Súmula TCU 281.

Trata-se, portanto, de um avanço interpretativo no âmbito do referido Tribunal de Contas, quase dez anos após a promulgação da Lei no 12.349/2010, sobretudo porque os agentes da Administração Pública pautam suas ações no entendimento jurisprudencial consolidado, com vistas a evitar eventual responsabilização administrativa. Assim, o cancelamento da Súmula TCU 281 representará um passo significativo para a consolidação do novo regramento de jurídico para a contratação de cooperativas de trabalho pela Administração Pública, que, atualmente, possui arcabouço legislativo suficiente para a sua implementação, pendente, no entanto, de suporte jurisprudencial que confira segurança jurídica para a Administração Pública.

\section{Discussões}

Diante da revisão acima delineada sobre os institutos jurídicos que tratam sobre os critérios e condições necessárias para a participação de cooperativas de trabalho em certames licitatórios, evidencia-se o avanço hermenêutico acerca da compreensão do cooperativismo e do papel desempenhado pelas cooperativas de trabalho, que, de maneira gradual, supera a concepção de instrumento fraudulento de intermediação de mão de obra, em detrimento dos direitos trabalhistas dos associados, e assume a concepção de instrumento eficaz para a promoção do desenvolvimento econômico e sustentável do país.

0 quadro 1 sintetiza os principais instrumentos jurídicos que ensejaram os entraves para a participação de cooperativas de trabalho em licitações públicas, e as alterações normativas que ocorreram durante o período de estudo e endossam o entendimento de que a cooperativa de trabalho constitui forma societária lícita, viável, cuja relação entre os cooperados encontra-se pautada nos princípios cooperativistas, que são a adesão livre e voluntária, gestão democrática, participação econômica dos membros, autonomia e independência, educação, formação e informação, intercooperação e interesse pela comunidade, que não se confundem com as relações trabalhistas (regidas pela Consolidação das Leis do Trabalho), cujos aspectos básicos relacionam-se com a hierarquia e a subordinação. 
Quadro 1. Institutos Jurídicos sobre a participação de cooperativas de trabalho em licitações públicas

\begin{tabular}{|c|c|}
\hline $\begin{array}{c}\text { INSTRUMENTO } \\
\text { NORMATIVO }\end{array}$ & CONSIDERAÇÕES DOS AUTORES \\
\hline $\begin{array}{c}\text { Súmula no } \\
\text { 331/2000 TST }\end{array}$ & $\begin{array}{l}\text { Determinava a responsabilidade subsidiária do tomador de serviços pelo mero } \\
\text { inadimplemento das obrigações trabalhistas, por parte do empregador, inclusive } \\
\text { quanto aos órgãos da Administração Pública. No entanto, a Súmula foi alterada em } \\
2011 \text {, para determinar que a responsabilidade subsidiária da Administração } \\
\text { Pública, nestes casos, ocorre apenas quando evidenciada conduta culposa no } \\
\text { cumprimento das obrigações da Lei n.o } 8.666 / 1993 \text {, especialmente } \\
\text { na fiscalização do cumprimento das obrigações contratuais e legais da prestadora } \\
\text { de serviço como empregadora. }\end{array}$ \\
\hline $\begin{array}{c}\text { Acordo De } \\
\text { Cooperação } \\
\text { Judicial/2003 } \\
\text { (MPT/UNIÃO) }\end{array}$ & $\begin{array}{l}\text { Firmado entre o Ministério Público do Trabalho (MPT) e a União, em 2003, nos } \\
\text { autos da Ação Civil Pública proposta perante a } 20^{\text {a }} \text { Vara do Trabalho de Brasília } \\
\text { (Processo 01082-2002-020-10-00-00), lista os serviços para os quais a } \\
\text { Administração Pública não pode contratar através de cooperativas, com o objetivo } \\
\text { de coibir a responsabilização da Administração Pública por atos praticados por } \\
\text { cooperativas fraudulentas. } \\
\text { Com a regulamentação das cooperativas de trabalho em 2012, entende-se que não } \\
\text { subsistem mais as condições fáticas que ensejaram a realização deste acordo, } \\
\text { razão pela qual ele não deve ser considerado como justificativa para inserção de } \\
\text { cláusulas restritivas à participação de cooperativas de trabalho em licitações } \\
\text { públicas. }\end{array}$ \\
\hline $\begin{array}{c}\text { Lei } \mathrm{n}^{\mathrm{o}} \\
12.349 / 2010\end{array}$ & $\begin{array}{l}\text { Institui o Princípio da promoção do desenvolvimento nacional sustentável no } \\
\text { âmbito das licitações públicas (Art. } 3^{\circ} \text {, caput, da Lei } \mathrm{n}^{\circ} \text { - 8666/93) e estabelece o } \\
\text { fortalecimento do caráter competitivo das licitações, inclusive no caso de } \\
\text { sociedades cooperativas (Art. } 3^{\circ}, \S^{\circ} \text { - I da Lei no } 8666 / 93 \text { ). }\end{array}$ \\
\hline $\begin{array}{l}\text { SUMULA TCU } \\
281 / 2012\end{array}$ & $\begin{array}{l}\text { Estabelece que "é vedada a participação de cooperativas em licitação quando, pela } \\
\text { natureza do serviço ou pelo modo como é usualmente executado no mercado em } \\
\text { geral, houver necessidade de subordinação jurídica entre o obreiro e o contratado, } \\
\text { bem como de pessoalidade e habitualidade". Entende-se que a Súmula deve ser } \\
\text { revisada, com a finalidade de apresentar melhor adequação às normas contidas na } \\
\text { Lei no } 12.690 / 2012 \text {. }\end{array}$ \\
\hline $\begin{array}{c}\text { Lei } \mathrm{n}^{\mathbf{0}} \\
12.690 / 2012\end{array}$ & $\begin{array}{l}\text { Representa o fortalecimento da identidade jurídica das cooperativas de trabalho, } \\
\text { cuja atuação baseia-se em princípios básicos do cooperativismo. Trata-se de } \\
\text { instrumento jurídico hábil para combater a utilização do sistema cooperativista } \\
\text { para a prática de condutas abusivas e fraudulentas. }\end{array}$ \\
\hline
\end{tabular}

Se em 2003, ao contratar cooperativas de trabalho, a Administração Pública assumia o risco de herdar a dívida trabalhista eventualmente deixada por cooperativas fraudulentas, atualmente este contexto encontra-se fortemente modificado, visto que em 2011 houve a alteração do item IV da Súmula 331/2000, que passou a exigir uma conduta culposa da Administração Pública, como a ausência de fiscalização dos contratos, para ensejar a responsabilidade pelo inadimplemento das obrigações trabalhistas. A Lei no 12.349/2010, que alterou o artigo $3^{\text {a }}$ da Lei $n^{0}$ 8.666/93, e a Lei $\mathrm{n}^{\mathrm{o}}$ 12.690/2012, por sua vez, são responsáveis por consolidar o direito de participação das cooperativas, em especial, das cooperativas de trabalho, no desempenho de atividades produtivas e econômicas desempenhadas no território nacional, em igualdade de condições com eventuais empresas e cooperativas concorrentes, sendo assegurado, inclusive, o direito de contratar com a Administração Pública.

Com isso, percebe-se que não subsistem mais as condições fáticas que ensejaram a homologação do Termo de Consolidação Judicial firmado entre o Ministério Público do Trabalho (MPT) e a União, em 2003 e entendimento diverso significa incorrer na síndrome de interpretação retrospectiva das leis (Gusmão, 2014) ferindo a nova ordem jurídica implementada para as Cooperativas de Trabalho.

A análise da jurisprudência do Tribunal de Contas da União (TCU) demonstra que, até 2017, o TCU mantém posicionamento firme contra a participação de cooperativas de trabalho em licitações públicas, ante o risco de responsabilidade da Administração Pública pelo inadimplemento das 
obrigações trabalhistas por parte da cooperativa de trabalho. Surpreende, no entanto, o fato doTCU manter este posicionamento restritivo, mesmo após a modificação da Súmula $\mathrm{n}^{\circ} 331$ TST em 2011, e publicação da Lei ํo 12.349/2010, que alterou o artigo 3a da Lei no 8.666/93, e da Lei no 12.690/2012, que estabelecem regras para as cooperativas de trabalho, demonstrando assim um entendimento que destoa dessas mudanças legislativas significativas para o desenvolvimento econômico.

No entanto, somente em 2019,Apenas em 2019, com a publicação do Acórdão 2463/2019Primeira Câmara, cuja análise detalhada encontra-se no capítulo anterior, o TCU consagra em sua jurisprudência as regras e princípios instituídas pelo Programa Nacional de Fomento às Cooperativas de Trabalho - PRONACOOP, de modo a não admitir a vedação à participação de cooperativas de trabalho em licitações públicas com base apenas na natureza do serviço a ser contratado e a recomendar a revisão da Súmula TCU 281.

Ao revisitar as normas e jurisprudências que tratam sobre a participação de cooperativas de trabalho em licitações públicas, verificou-se que, no Brasil, historicamente, as cooperativas de trabalho, que atuam de forma regular e em conformidade com os princípios cooperativistas, para se consolidar no mercado e garantir o acesso às contratações com o poder público, enfrentam uma barreira construída em decorrência da má-fama propagada pela atuação de cooperativas fraudulentas.

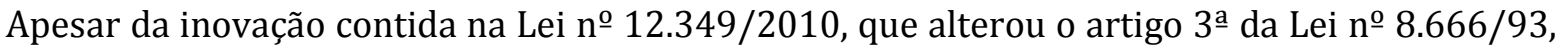
e na Lei no 12.690/2012, na prática, a aplicabilidade destes instrumentos normativos se apresenta de forma lenta e conflita com jurisprudências e normas anteriores, ainda utilizadas como fundamento jurídico de forma equivocada, o que requer dos gestores de cooperativas e operadores do Direito Cooperativo especial atenção para os caminhos adotados pelos órgãos públicos, com o fito de tomar as medidas administrativas e judiciais necessárias pra impedir a publicação de editais de licitação com cláusulas restritivas à participação de cooperativas de trabalho, ou seja, cláusulas em desconformidade com a livre concorrência e a ampla competitividade que deve ser conferida aos certames licitatórios, e, sobremaneira, com o princípio da promoção do desenvolvimento nacional sustentável, para o qual as cooperativas de trabalho se apresentam como importante instrumento de consolidação e implementação de práticas sustentáveis.

\section{Conclusões}

A ordem constitucional vigente considera o sistema cooperativista como mecanismo capaz de promover o desenvolvimento socioeconômico e socioambiental do país, devido a correlação intrínseca existente entre os princípios cooperativistas, os princípios da república e os Objetivos de Desenvolvimento Sustentável (ODS). As cooperativas de trabalho, por sua vez, desempenham papel fundamental para o desenvolvimento de políticas públicas sustentáveis, ao possibilitar aos trabalhadores o exercício das atividades profissionais com proveito comum, autonomia e autogestão para a obtenção de melhor qualificação, renda, situação socioeconômica e condições gerais de trabalho.

Embora as cooperativas de trabalho tenham adquirido identidade jurídica com o advento da Lei no 12.690/2012, que instituiu o Programa Nacional de Fomento às Cooperativas de Trabalho PRONACOOP, estas ainda sofrem restrições para a participação em certames licitatórios, criadas com o intuito de diminuir o risco para a Administração Pública, decorrentes da atuação fraudulenta de "cooperativas" de intermediação de mão-de-obra.

Com a discussão desenvolvida no presente artigo restou evidenciado que as restrições estabelecidas para a participação de cooperativas de trabalho nos certames licitatórios não se coadunam com o novo regramento jurídico para a contratação de cooperativas de trabalho pela Administração Pública, sobretudo porque há expressa previsão constitucional e legal para o estímulo ao cooperativismo, com a possibilidade de constituição de cooperativas de trabalho com qualquer objeto social e com permissão para a participação em licitações públicas em igualdade de condições com os demais concorrentes. Em outras palavras, a participação das cooperativas de trabalho em 
certames licitatórios não constitui uma mera faculdade, sujeita à discricionariedade da Administração Pública, mas um direito, assegurado constitucional e legalmente.

Ressalte-se que a promoção do desenvolvimento nacional sustentável corresponde a uma das finalidades do procedimento licitatório, fazendo-se necessário, para alcança-lo, garantir a correta aplicação de outros princípios, tais como, a isonomia, vantajosidade e competitividade. Nesse sentido, não é razoável a aplicação de restrições à participação de licitantes, com fulcro apenas na natureza jurídica do licitante ou na natureza do serviço prestado.

Assim, o Termo de Conciliação Judicial firmado entre o Ministério Público do Trabalho (MPT) e a União, em 2003, nos autos da Ação Civil Pública proposta perante a $20^{\text {a }}$ Vara do Trabalho de Brasília (Processo 01082-2002-020-10-00-00) é revestido de vícios de legalidade e constitucionalidade, desde o seu surgimento no ordenamento jurídico, seja por infringir o artigo 174 da Constituição Federal de 1988, seja por infringir a competitividade dos certames licitatórios, quando a legislação já previa medida cabível para combater a prática de atos fraudulentos pelas pessoas jurídicas contratadas pela Administração Pública, qual seja, o dever de fiscalização da execução dos contratos.

A Lei $n^{0}$ 12.349/2010, que alterou o artigo $3^{\text {a }}$ da Lei $n^{0}$ 8.666/93, e a Lei $n^{0}$ 12.690/2012 representam a superação das condições fáticas que ensejaram a homologação do supracitado Termo de Conciliação Judicial e a edição da Súmula TCU 281, razão pela qual conclui-se pelo seu afastamento do ordenamento jurídico brasileiro. Não obstante, a jurisprudência majoritária dos Tribunais de Contas e Tribunais Superiores ainda permite a aplicação de restrições à participação de cooperativas em certames licitatórios, sem realizar uma análise pormenorizada a respeito do tema.

A publicação do Acórdão 2463/2019-Primeira Câmara - TCU, Ministro Relator Bruno Dantas, que considerou incoerente a vedação à contratação de cooperativas de trabalho com base apenas no gênero de serviço a ser prestado, contribuiu para a renovação do debate e representa significativo posicionamento jurídico, capaz de ensejar o cancelamento da Súmula TCU 281, medida aqui defendida, em decorrência da necessidade de atribuir máxima eficácia à nova normatização que consagra as cooperativas como forma societária capaz de promover o desenvolvimento nacional sustentável, sendo-lhe garantida a participação na atividade econômica do país, inclusive no que se refere a possibilidade contratar com a Administração Pública.

\section{Referências}

BRASIL. Instrução Normativa $\mathrm{n}^{\mathrm{o}} 02$ de 30 deaAbril de 2008 . Disponível em: https://www.governodigital.gov.br/documentos-e-arquivos/legislacao/11\%20-

\%20IN\%2002\%2030-04-08.pdf/view. Acesso em: 15 nov 2019.

BRASIL. Instrução normativa $\mathrm{n}^{\mathrm{0}} 5$, de 26 de maio de 2017. Disponível em: http://www.in.gov.br/materia/-/asset_publisher/Kujrw0TZC2Mb/content/id/20239255/do1-201705-26-instrucao-normativa-n-5-de-26-de-maio-de-2017-20237783. Acesso em: 15 nov 2019.

BRASIL. Lei no 12.349, de 15 de dezembro de 2010. Disponível em: http://www.planalto.gov.br/ccivil_03/_ato2007-2010/2010/lei/l12349.htm. Acesso em: 7 jun 2019.

BRASIL. Lei no 12.690, de 19 de julho de 2012. Disponível em: http://www.planalto.gov.br/ccivil_03/_ato2011-2014/2012/lei/l12690.htm. Acesso em: 7 jun 2019.

BRASIL. Lei № 8.666, De 21 De Junho De 1993. Disponível em: http://www.planalto.gov.br/ccivil_03/leis/18666cons.htm. Acesso em: 7 jun 2019.

BRASIL. Lei no 8.949, de 9 de dezembro de 1994. Disponível em: http://www.planalto.gov.br/ccivil_03/LEIS/L8949.htm. Acesso em: 7 jun 2019. 
BRASIL. Projeto de Lei. no 7009/2006. Disponível em: https://www.camara.leg.br/proposicoesWeb/prop_mostrarintegra;jsessionid=6D362C0EFFE7196D8 A32010341302A04.proposicoesWebExterno1?codteor=394217\&filename=TramitacaoPL+7009/2006. Acesso em: 16 nov 2019.

BRASIL. Superior Tribunal de Justiça. REsp 1204186/RS, Rel. Ministra ELIANA CALMON, SEGUNDA TURMA, julgado em 18/10/2012, DJe 29/10/2012 Disponível em: http://www.stj.jus.br/SCON/jurisprudencia/toc.jsp?livre=1204186\&\&tipo_visualizacao=RESUMO\&b= ACOR. Acesso em: 07 jun. 2019.

BRASIL. Tribunal de Contas da União. Acórdão 2221/2013-Plenário. Disponível em: https://pesquisa.apps.tcu.gov.br/\#/documento/acordaocompleto/Ac\%25C3\%25B3rd\%25C3\%25A3 o\%25202221\%252F2013Plen\%25C3\%25A1rio./\%20/DTRELEVANCIA\%20desc,\%20NUMACORDAOI NT\%20desc/0/\%20?uuid=4c9b38d0-8954-11e9-b328-e9a0bb035556. Acesso em: 07 jun. 2019.

BRASIL. Tribunal de Contas da União. Acórdão 2260/2017-Primeira Câmara. Disponível em: https://pesquisa.apps.tcu.gov.br/\#/documento/acordaocompleto/Ac\%25C3\%25B3rd\%25C3\%25A3 o\%25202260\%252F2017Primeira\%2520C\%25C3\%25A2mara/\%20/DTRELEVANCIA\%20desc,\%20 NUMACORDAOINT\%20desc/0/\%20?uuid=4c9b38d0-8954-11e9-b328-e9a0bb035556.Acesso em: 07 jun. 2019.

BRASIL. Tribunal de Contas da União. Acórdão 2463/2019-Primeira Câmara, DF, 19 mar. 2019. Disponível em: https://pesquisa.apps.tcu.gov.br/\#/documento/acordaocompleto/*/NUMACORDAO:2463\%20ANOACORDAO:2019\%20COLEGIAD0:\%22Primeira\%20C\%C3 \%A2mara\%22/DTRELEVANCIA\%20desc,\%20NUMACORDAOINT\%20desc/0/\%20. Acesso em: 05 jun. 2019.

BRASIL. Tribunal de Contas da União. Acórdão 5736/2011-Primeira Câmara. Disponível em: https://pesquisa.apps.tcu.gov.br/\#/documento/acordaocompleto/*/NUMACORDA0\%253A5736\%25 20ANOACORDA0\%253A2011/DTRELEVANCIA\%20desc,\%20NUMACORDAOINT\%20desc/1/\%20?uu $\mathrm{id}=4 \mathrm{c} 9 \mathrm{~b} 38 \mathrm{~d} 0-8954-11 \mathrm{e} 9-\mathrm{b} 328-\mathrm{e} 9 \mathrm{a} 0 \mathrm{bb} 035556$. Acesso em: 07 jun. 2019.

BRASIL. Tribunal de Contas da União. Súmula 281. Disponível em: <https://pesquisa.apps.tcu.gov.br/\#/documento/sumula/S\%25C3\%25BAmula\%2520281/\%20/DTR ELEVANCIA\%20desc,\%20NUMEROINT\%20desc/0/\%20?uuid=4c9b38d0-8954-11e9-b328e9a0bb035556. Acesso em: 07 jun. 2019.

BRASIL. Tribunal Superior do Trabalho. Súmula 331. Disponível em: http://www3.tst.jus.br/jurisprudencia/Sumulas_com_indice/Sumulas_Ind_301_350.html. Acesso em: 07 jun. 2019.

BRASIL. Constituição Federal de 1988. Promulgada em 5 de outubro de 1988. Disponível em http://www.planalto.gov.br/ccivil_03/constituicao/constituicaocompilado.htm. Acesso em: 7 jun 2019.

CARVALHO FILHO, José dos Santos. Manual de Direito Administrativo. 26a ed. São Paulo: Atlas, 2013.

CARVALHO, Matheus. Manual de Direito Administrativo. 3로 ed. Salvador: JusPODIVM, 2016.

COOPERATIVA. Plano de ação para uma década. Disponível em: https://www.ica.coop/sites/default/files/publication-files/ica-blueprint-final-june-2013-portuguese975329096.pdf. Acesso em 27 abr 2020. 
GARCIA, Flávio Amaral; RIBEIRO, Leonardo Coelho. Licitações Públicas Sustentáveis. Revista de Direito Administrativo, Rio de Janeiro, V. 260, p. 231-254, maio/ago.2012, p. 238. Disponível em: http://bibliotecadigital.fgv.br/ojs/index.php/rda/article/viewFile/8836/7629. Acesso em: 05 jun. 2019.

GUSMÃO, Diego Da Fonseca Hermes Ornellas De. As Cooperativas de Trabalho nas Licitações Públicas - Uma Necessária Mudança de Paradigma. Revista da AGU, Brasília-DF, ano XIII, n. 39, p. 110-132, jan./mar. 2014. Disponível em: https://seer.agu.gov.br/index.php/AGU/article/view/6/2. Acesso em: 05 jun. 2019.

LEITE, Glaucia Silva. AMARAL, Ana Paula Martins. O cooperativismo no contexto da ordem econômica e as perspectivas de desenvolvimento nacional. Derecho y Cambio Social, Ano 10, №. 34, 2013.

OURO-SALIM, Omar. BA, Serigne Ababacar Cisse. ROSALEM, Vagner. Impacto socioeconômico das cooperativas: contribuição para um mundo melhor. Revista de Gestão e Organizações Cooperativas RGC, Santa Maria, v.5, n.10, p.189-202, Jul./Dez. 2018.

PARE, Abel Moreira. Intercooperação A formação das redes flexíveis como estratégia competitiva inteligente. Porto Alegre: Sescoop/RS, 2010.

PRADO, Aurélio. Cooperativas de mãos dadas com os ODS. Sistema OCB, Brasília: 28 de agosto de 2018. Disponível em:https://somoscooperativismo.coop.br/noticia/21179/cooperativas-de-maos-dadascom-os-ods. Acesso em: 26 abr. 2020.

SANTOS, Raimundo Bonfim dos. Participação em cooperativas e associações: o porquê das pessoas se filiarem. Ilhéus: Editus, 2016.

SCHNEIDER, J.O. Cooperativismo e desenvolvimento sustentável. Otra Economía, 9 (16): 94-104, 2015. Disponível em: http://revistas.unisinos. br/index.php/ otraeconomia/article/viewFile/. Acesso em: 05 jun. 2019.

SISTEMA OCB - NÚCLEO DE INFORMAÇÕES E MERCADO. Anuário do Cooperativismo Brasileiro. 3aㅗ versão. Brasília - DF. Disponível em: https://somoscooperativismo.coop.br/publicacao/57/ramos-docooperativismo. Acesso em: 15 nov 2019.

SISTEMA OCB - NÚCLEO DE INFORMAÇÕES E MERCADO. Ramos do co. 3a versão. Brasília - DF. Disponível em: https://somoscooperativismo.coop.br/publicacao/57/ramos-do-cooperativismo. Acesso em: 15 nov 2019.

PLATAFOMRA. Cops. Disponível em: http://www.coopsfor2030.coop/pt/about. Acesso em 27 abr 2020. 